\title{
SYNTHESIS AND MESOMORPHIC PROPERTIES OF NEW ROD-LIKE HETEROCYCLIC LIQUID CRYSTALS
}

\author{
KOK-LEEI FOO ${ }^{a}$, SIE-TIONG HA ${ }^{\mathrm{a},{ }^{*},}$, GUAN-YEOW YEAP ${ }^{\mathrm{b}}$ \\ and HONG-CHEU LIN"
}

\begin{abstract}
Structure-property relationship is one of the most important research areas in the liquid crystals. Therefore, in the present work, we studied a new series of rod-like heterocyclic liquid crystals, 6-methyl-2-[4-(4alkoxybenzoyloxy)benzylideneamino]benzothiazoles. The rod-like molecules having heterocyclic and two phenyl rings as core system, imine and ester as linking units, long alkoxy chain at the terminal position. There are six members in the series with different length of alkoxy chain $\left(\mathrm{C}_{n} \mathrm{H}_{2 n+1} \mathrm{O}\right.$-, where $n=6,8,10$, $12,14,16)$. The structures of the compounds were elucidated using spectroscopic techniques. Their mesomorphic behaviours were determined by differential scanning calorimetry, polarizing optical microscopic and powder X-ray diffraction techniques. Members with shorter alkoxy chain $(n=6,8,10)$ exhibited single mesophase (nematic). As the alkoxy chain increased to $n=12,14,16$, the nematic phase appeared together with an additional mesophase (smectic). The phase width was dependent on the alkoxy chain length. The incorporation of the methyl substituent at the sixth position (lateral) of the benzothiazole able to increase the clearing point and widen the mesophase width of the compounds.
\end{abstract}

Keywords: benzothiazole, Schiff base, nematic, smectic A

\section{INTRODUCTION}

Heterocyclic-based liquid crystal (LC) is of current interest due to its potential applications as photoconductive materials, fluorescent compounds and thin-film organic-field-effect transistors [1-4]. Earlier work on rod-like or

\footnotetext{
a Faculty of Science, Universiti Tunku Abdul Rahman, JIn Universiti, Bandar Barat, 31900 Kampar, Perak, Malaysia.

b Liquid Crystal Research Laboratory, School of Chemical Sciences, Universiti Sains Malaysia, 11800 Minden, Penang, Malaysia.

c Department of Materials Science \& Engineering, National Chiao Tung University, 1001 TaHsueh Road, Hsinchu 300, Taiwan, ROC.

*Corresponding author: hast_utar@yahoo.com, hast@utar.edu.my
} 
calamitic LCs has been focused on low-molar mass liquid crystals possessing only phenyl rings and the current trend is shifted to the phenyl structures with inclusion of heterocycles. This is not only due to the better potential with heterocycles for the formation of new mesogens, but also because the addition of heteretoatoms strongly affects the mesophase formation [5-7]. The presence of heteroatoms ( $\mathrm{S}, \mathrm{O}$ and $\mathrm{N}$ ) can greatly alter the polarity, polarizability and sometimes the geometric shape of the molecule, thus controlling the type of mesophase, phase transition temperatures, dielectric and other properties of the mesogenic molecules [8]. A few examples of heterocyclic rings used as a core system include benzothiazole [9], 1,3,4-thiadiazole [10,11] and pyridine [12-14].

Mesomorphic behavior can be varied by modifying its molecular structure including linking, terminal and core groups. Imine (or Schiff base), a linking group is usually incorporated into the molecular structure to increase the length and polarisability anisotropy of the molecular core in order to enhance the phase stability [15]. Other linking groups such as ester [16-20], cinnamate [21-23], or chalcone [24] which was incorporated together with the imine linker has received much attentions owing to interesting properties and substantial temperature range.

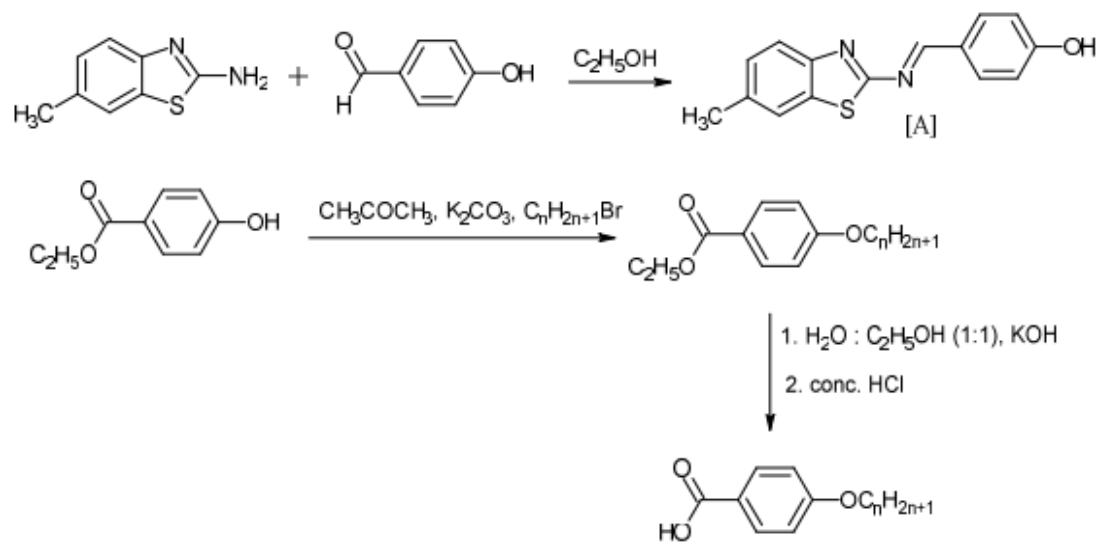

[B]

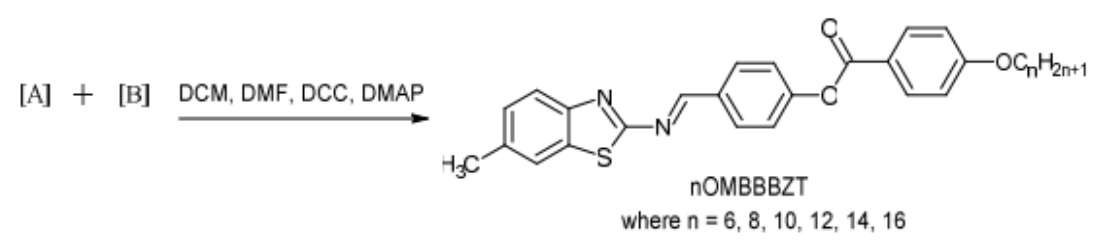

Scheme 1. Synthetic of heterocyclic liquid crystals, nOMBBBZT. Yield: $n=6$ $(40 \%), n=8(46 \%), n=10(51 \%), n=12(46 \%), n=14(59 \%), n=16(63 \%)$. 
In this paper, we report another new homologous series of heterocyclic benzothiazole-imine-ester based liquid crystals (Scheme 1). The current structure is closely related to the structures (compounds $\mathbf{D}$ and $\mathbf{E}$ in Table 3 ) reported in our previous works $[25,26]$. Structure modification at the benzothiazole ring with the incorporation of a methyl substituent in the current compound can increase the clearing point and nematic phase width of the compounds. Although it is a minor modification in its molecular geometry, it has brought significant changes to its mesomorphic properties.

\section{RESULTS AND DISCUSSION}

\section{EI-MS Data}

EI-MS analysis were carried out on two representative compounds, $12 \mathrm{OMBBBZT}$ and 16OMBBBZT. The prominent molecular ion peaks at $\mathrm{m} / \mathrm{z} 556.4$ (Fig. 1a) and 612.4 (Fig. 1b) established its molecular formula as $\mathrm{C}_{34} \mathrm{H}_{40} \mathrm{~N}_{2} \mathrm{O}_{3} \mathrm{~S}$ and $\mathrm{C}_{38} \mathrm{H}_{48} \mathrm{~N}_{2} \mathrm{O}_{3} \mathrm{~S}$ supporting the proposed structure of 12OMBBBZT and 16OMBBBZT, respectively. Both compounds showed base peak of phenyl acylium ion at $\mathrm{m} / \mathrm{z} 289.2$ and 345.3, respectively.

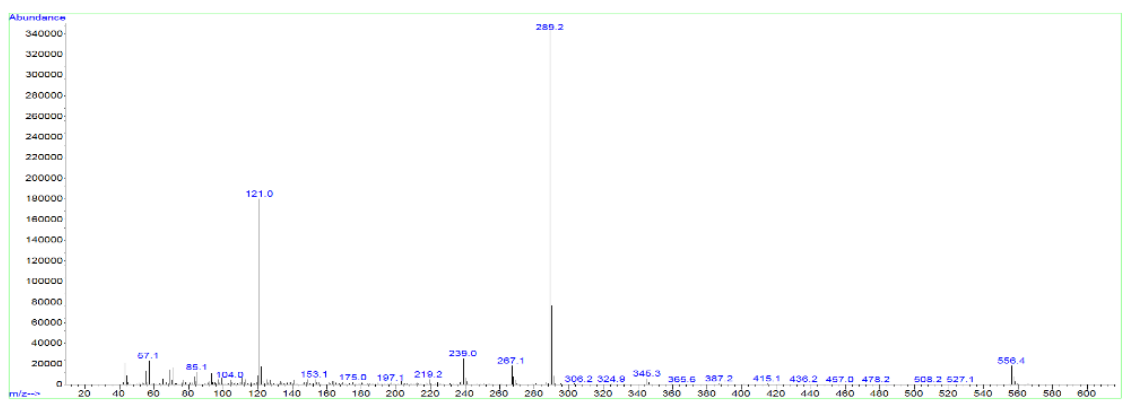

(a)

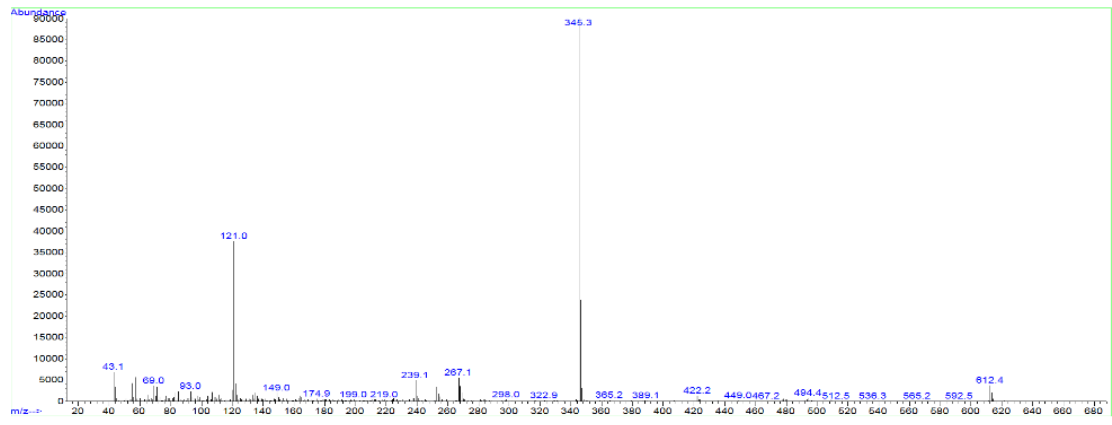

(b)

Figure 1. El mass spectra of (a) 12OMBBBZT and (b) 16OMBBBZT. 


\section{IR and NMR Spectral Data}

Based on FT-IR spectral data of 14OMBBBZT, the presence of two strong peaks at the frequencies of 2921 and $2851 \mathrm{~cm}^{-1}$ can be attributed to the long alkoxy groups. This indicates that the terminal phenolic hydroxy group $(-\mathrm{OH})$ attached at one end of the intermediate was replaced by terminal alkoxy chain $\left(-\mathrm{OC}_{n} \mathrm{H}_{2 n+1}\right)$. The presence of $\mathrm{C}=\mathrm{N}$ bond of imine is confirmed based on the band with strong intensity at $1601 \mathrm{~cm}^{-1}$. This absorption band is overlapped with the band arising from the $\mathrm{C}=\mathrm{N}$ of the benzothiazole ring, therefore, it resulted in a sharp and strong absorption band [27]. Aromatic $\mathrm{C}=\mathrm{C}$ functional group showed its band at $1576 \mathrm{~cm}^{-1}$ with medium intensity. Another strong absorption band at $1726 \mathrm{~cm}^{-1}$ is ascribed to the ester functional group that connected between two aromatic rings. Band due to the stretching of ether, C-O-C bond can be found as strong band at $1252 \mathrm{~cm}^{-1}$.

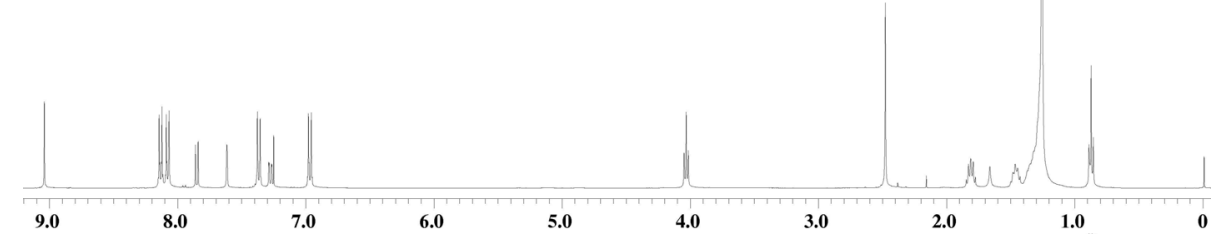

(a)

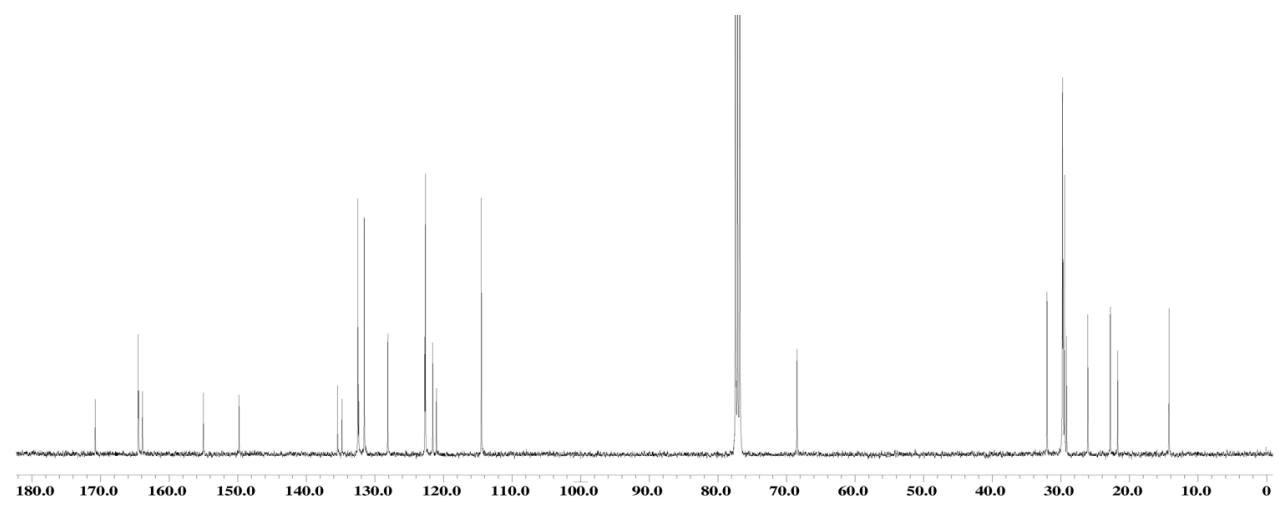

(b)

Figure 2. ${ }^{1} \mathrm{H}$ NMR (a) and ${ }^{13} \mathrm{C}$ NMR (b) spectra of $140 M B B B Z T$.

In the ${ }^{1} \mathrm{H}$ NMR spectrum (Fig. 2a) of $14 \mathrm{OMBBBZT}$, two triplets at $\delta$ 0.88 and $\delta 4.03$, were respectively belonged to the methyl $\left(\mathrm{C}_{3}\right)$ protons and methylene protons that directly bonded to oxygen atom $\left(-\mathrm{C}_{2} \mathrm{O}-\mathrm{Ar}\right)$. Another methylene protons (- $\left.\mathrm{CH}_{2}-\mathrm{C}_{2}-\mathrm{CH}_{2}-\mathrm{O}-\right)$ showed its presence as quintet signal at $\delta$ 1.81. Balance of protons of the long alkoxy chain showed multiplet signal 
at chemical shifts range of $1.26-1.50 \mathrm{ppm}$. A singlet signal at $\delta 2.48$ is belonged to the methyl group that attached to the aromatic ring. Four doublet signals with each integration of two protons appeared at $\delta 6.97,7.37,8.09$ and 8.14 were assigned to the two para-substituted aromatic rings. Three protons at the benzene ring that fused to thiazole ring showed three distinct signals at $\delta 7.28,7.62$ and 7.85 with doublet, singlet and doublet splittings, respectively. A singlet signal at the most downfield region, $\delta 9.04$, confirmed the presence of the imine linking group [28].

The molecular structure of 14OMBBBZT was further verified by using ${ }^{13} \mathrm{C}$ NMR spectroscopy (Fig. 2b). The peak at $\delta 14.25$ was belonged to the methyl carbon of the alkoxy chain while the peaks between $\delta 22.80-68.48$ was assigned to the methylene carbons of the long alkoxy chain. The methyl carbon that attached to the benzene ring is appeared at $\delta 21.72$. Fourteen aromatic carbons are resonated between $\delta 114.49$ and 163.90. The presence of $\mathrm{C}=\mathrm{N}$ of thiazole and $\mathrm{C}=\mathrm{N}$ of azomethine groups are confirmed based on the peaks appeared at $\delta 164.47$ and 164.53. Another important signal resonated at $\delta 170.78$ is belonged to the $\mathrm{C}=\mathrm{O}$ of ester.

\section{Mesomorphic Properties}

The mesophases of the compounds were identified using an polarizing optical microscope during heating cycle. The optical photomicrographs of 8OMBBBZT and 16OMBBBZT are shown in Fig. 3 as representative illustrations. Observation of 8OMBBBZT upon heating it from its crystal phase, showed the presence of single mesophase. The droplets texture (Fig. 3a) is identified as nematic phase. As for 16OMBBBZT, it exhibited two types of mesophases. On heating, fan-shaped texture of smectic $A(\mathrm{SmA})$ phase (Fig. $3 b)$ was first observed. The SmA phase has been identified based on the optical textures in which regions of fan-shaped and homeotropic (dark area) textures coexist [29]. On further heating of 16OMBBBZT, it turned into nematic phase with Schlieren texture (Fig. 3c) on further heating. All observed textures are typical according to the literature [30,31].

The phase transition temperatures and associated enthalpy changes of nOMBBBZT were obtained using a differential scanning calorimeter. Fig. 4 shows the DSC thermograms of representative compounds, 10OMBBBZT and 12OMBBBZT. The data are summarized in Table 1. All the compounds exhibited enantiotropic properties. Their endotherms were characterized by the crystal-mesophase-isotropic transitions occurring above the melting temperatures recorded during the heating cycle. Such transitions were also supported by the enthalpy values of the respective compounds. 


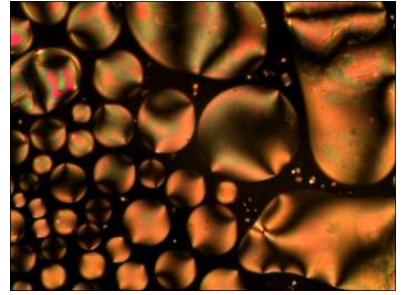

(a)

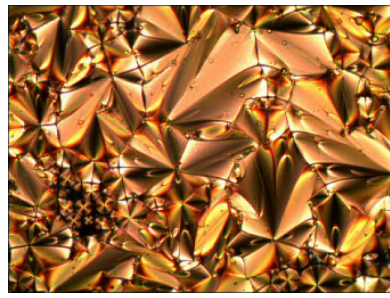

(b)

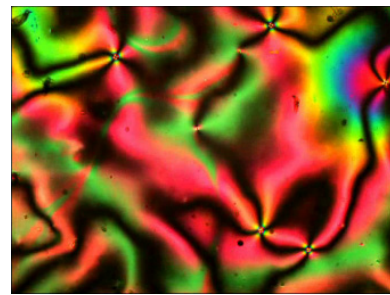

(c)

Figure 3. (a) Optical photomicrograph of 8OMBBBZT exhibiting droplets texture of nematic phase. (b) Optical photomicrograph of 16OMBBBZT exhibiting fanshaped texture of SmA phase. (c) On further heating of 16OMBBBZT, it turned into Schlieren texture of nematic phase

Table 1. Transition temperatures and associated enthalpy changes of nOMBBBZT

\begin{tabular}{|c|c|}
\hline Compound & Transition Temperatures, ${ }^{\circ} \mathrm{C}\left(\Delta \mathrm{H}, \mathrm{kJ} \mathrm{mol}^{-1}\right)$ \\
\hline 6OMBBBZT & $\mathrm{Cr}_{1} 121.7(30.0) \mathrm{Cr}_{2} 140.8$ (35.2) N 255.1 (27.0) I \\
\hline 8OMBBBZT & Cr 130.5 (33.3) N 215.2 (1.7) I \\
\hline 10OMBBBZT & $\mathrm{Cr}_{1} 93.7(17.9) \mathrm{Cr}_{2} 123.8(26.8) \mathrm{N} 221.9(0.6) \mathrm{I}$ \\
\hline 12OMBBBZT & $\mathrm{Cr}_{1} 81.3(8.2) \mathrm{Cr} 2110.6(29.1) \mathrm{SmA} 161.8(0.7) \mathrm{N} 217.9(1.2) \mathrm{I}$ \\
\hline 14OMBBBZT & $\mathrm{Cr}_{1} 96.7(12.4) \mathrm{Cr}_{2} 109.7(25.4) \mathrm{SmA} 179.2(0.4) \mathrm{N} 216.5(0.9) \mathrm{I}$ \\
\hline 16OMBBBZT & $\mathrm{Cr}_{1} 86.5(27.3) \mathrm{Cr}_{2} 104.1(32.5) \mathrm{SmA} 179.2(1.3) \mathrm{N} 198.7(1.2) \mathrm{I}$ \\
\hline
\end{tabular}

Notes: $\mathrm{Cr}=$ crystal; $\mathrm{I}=$ isotropic liquid; $\mathrm{N}=$ nematic; $\mathrm{SmA}=$ smectic $\mathrm{A}$.

Two types of phase transition sequences were observed. First, a single mesophase (nematic) was observed for the early three member of the series $(n=6,8,10)$. The phase sequence of Cr-to-N-to-I is well reflected in the DSC thermogram of 10OMBBBZT (Fig. 4a). The second type of phase transition sequence was observed for the later members. The SmA phase started to emerge in the later members $(n=12,14,16)$ along with the nematic phase. The phase sequence of Cr-to-SmA-to-N-to-I is illustrated in the DSC thermogram of 120MBBBZT (Fig. 4b). 


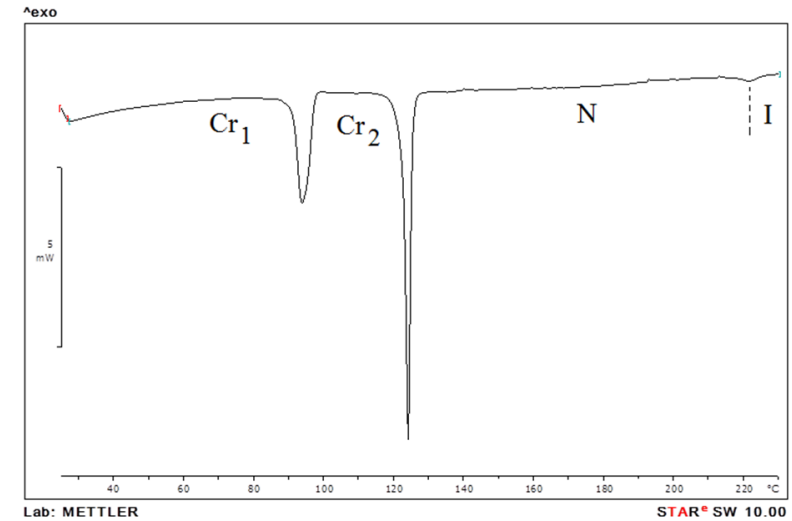

(a)

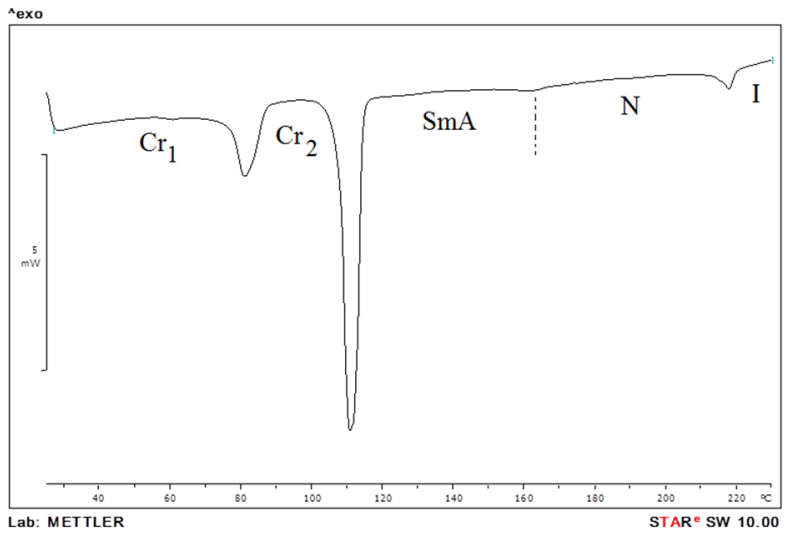

(b)

Figure 4. DSC thermograms of (a) 10OMBBBZT and (b) $120 M B B B Z T$ during heating scan.

\section{$X$-Ray Diffraction Analysis}

The SmA phase has been further verified on the representative compound $16 \mathrm{OMBBBZT}$ via XRD analysis. The XRD diffractogram of $16 \mathrm{OMBBBZT}$ is shown in Fig. 5 whereas the XRD data is tabulated in Table 2. For a smectic phase, it is basically known that a sharp and strong peak appears at low angle $\left(1^{\circ}<2 \theta<4^{\circ}\right)$ in small-angle X-ray scattering curve and a broad peak associated with lateral packing at $2 \theta \approx 20^{\circ}$ can be spotted in wide-angle $X$-ray diffraction curve. On the other hand, for the nematic phase, there will be no peak appeared at low angle and a broad peak at $2 \theta \approx 20^{\circ}$ can be observed in the XRD diffractogram [32]. 
As from XRD pattern of the current compound, 16OMBBBZT, it can be seen that a single sharp diffraction peak appeared at $2 \theta=1.35^{\circ}$ together with a broad peak at wide angle $\left(2 \theta \approx 13^{\circ}\right)$. This typical XRD pattern indicates the presence of a lamellar structure (smectic layered arrangement) for liquid crystal phase $[33,34]$.

Table 2. Powder X-ray diffraction data of $160 \mathrm{MBBBZT}$

\begin{tabular}{|c|c|}
\hline 2 theta $\left(^{\circ}\right)$ & 1.35 \\
\hline$d$-spacing & $43.1 \AA$ \\
\hline$L$ & $40.75 \AA$ \\
\hline$d / L$ & 1.06 \\
\hline Phase & SmA \\
\hline Arrangement & Monolayer \\
\hline
\end{tabular}

Combining the data from POM and XRD, types of smectic phase can be confirmed. Based on the XRD data, the $d$-layer spacing was found to be $43.1 \AA$ whereas the molecular length $(L)$ obtained from the MM2 molecular calculation is $40.75 \AA$, where $d$ is the layer spacing and $L$ is the molecular length. Hence, the $d / L$ ratio was calculated to be 1.06 which is approximate to 1 . As a general rule, when the layer spacing is approximate to the molecular length $(d \sim L)$, the SmA phase is identified as monolayer type [35]. Thus, the SmA phase exhibited in 16OMBBBZT was said to be monolayer arrangement. Similar results were obtained for azine-type mesogens reported by Wei and coworkers [36].

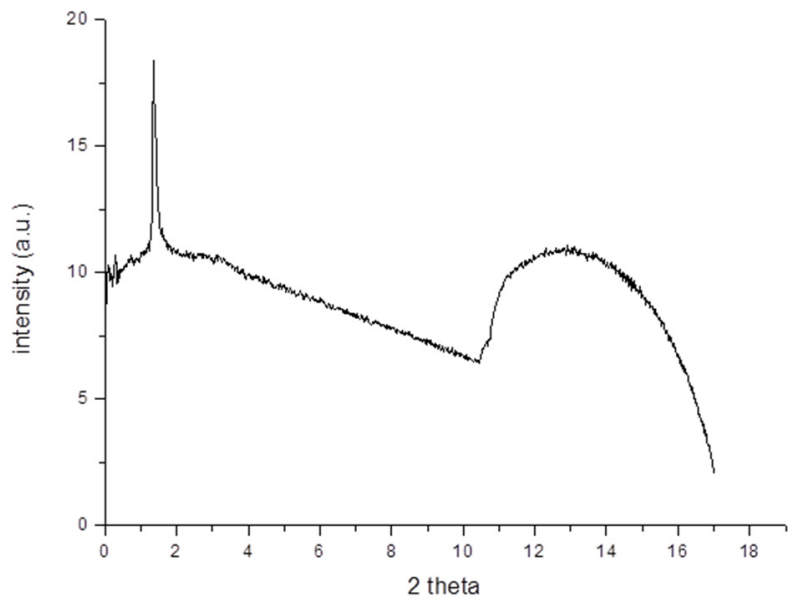

Figure 5. X-ray diffractogram of 16OMBBBZT. 


\section{Structure-Mesomorphic Property Relationships}

Influence of the length of alkoxy chain on the mesomorphic properties can be established based on the graph of the phase transition temperature against the number of carbons in the alkoxy chain (Fig. 6). As the alkoxy chain lengthens, the melting and clearing temperatures exhibited a gradual descending trend. It was due to the dilution of the mesogenic core by the long carbon chain $[37,38]$. Suitable ratio between length and width of the molecule is an important factor for the molecules to display mesophase. All the members of the current homologue series exhibited enantiotropic phases, even the compounds with the shortest alkoxy chain $(n=6)$ where the nematic phase appeared. Hence, it indicates that the current molecule is a potential mesogenic core that worth to be further explored for design of new liquid crystalline molecules.

Smectic phase is generally observed for higher members of a series as the longer alkoxy chain is able to intertwine and facilitate the smectic phase formation [39]. In addition, the ester linking group that provided greater dipole-dipole interaction and subsequently encouraged the lateral packing and arranged themselves in the smectic phase. As the number of carbons at the alkoxy chain reached $n=12$, an additional phase (SmA) emerged together with the nematic phase. It can therefore be suggested that in order to generate the smectic phase in the analogous substituted $\mathrm{C}_{6} \mathrm{H}_{4} \mathrm{COOC}_{6} \mathrm{H}_{4} \mathrm{C}(\mathrm{H})=\mathrm{NC}_{7} \mathrm{H}_{4} \mathrm{NS}$ compounds, the number of carbons in the alkoxy chain must be at least 12 $(n \geq 12)[40]$.

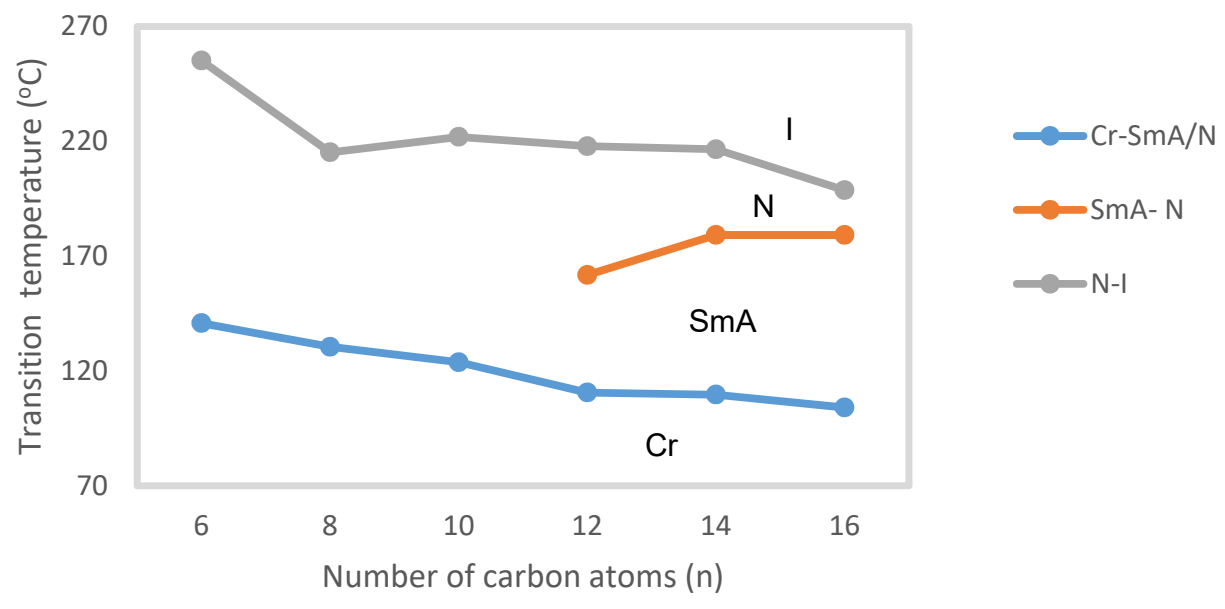

Figure 6. Graph of phase transition temperature against the number of carbon atoms ( $n$ ) in alkoxy chain. 
Phase width of liquid crystals can also be controlled by the length of terminal chain. The plot of phase width against the number of carbons in the alkoxy chain is depicted in Fig. 7. It is clearly shown that the nematic phase width decreased while the smectic phase width increased as the alkoxy chain lengthened. The last member of the series, 16OMBBBZT with the longest alkoxy chain possessed the narrowest nematic phase width $\left(\Delta \mathrm{N}=19.5^{\circ} \mathrm{C}\right)$ and the largest smectic phase width $\left(\triangle \mathrm{SmA}=75.1^{\circ} \mathrm{C}\right)$. Therefore, for the current molecular core structure, it can be proposed that the suitable terminal chain length that give the widest SmA phase is C16, while the widest nematic phase was possessed by the member with the shortest alkyl chain length $\left(\mathrm{C} 6, \Delta \mathrm{N}=114.3^{\circ} \mathrm{C}\right)$.

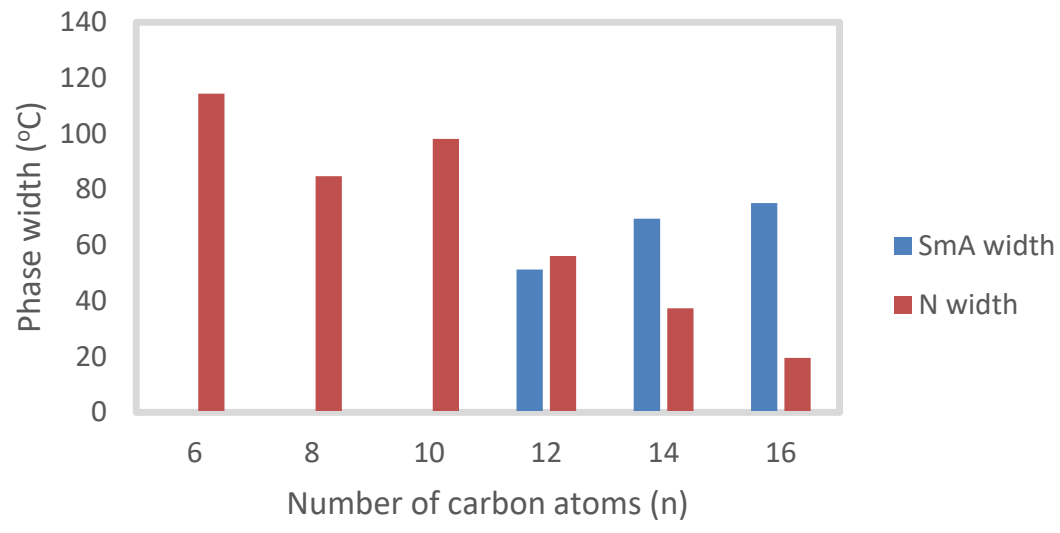

Figure 7. Plot of mesophase width against the number of carbons in alkoxy chain.

\section{Comparison with Related Compounds}

The reported examples revealing the influence of molecular geometry on the mesomorphic property usually involve contribution from molecular packing effects. The model system that will give a clear illustration on how molecular geometry affects the mesomorphic property will usually attract much attention. Table 3 shows the comparison of mesomorphic properties between the reported compounds A [41], B [27], C [42], D [26] and E [25] with the present compound, 12OMBBBZT. Molecules with two rings, compounds $\mathbf{A}$ and $\mathbf{B}$ with an aromatic ring connected to a benzothiazole ring via Schiff base linker exhibited SmA phase with lower clearing point compare to molecules with three rings (12OMBBBZT, C, D and E). Among the molecules with two rings, it was found that the different linking groups that attached to the alkyl chain (ether group in compound $\mathbf{A}$ and ester group in compound $\mathbf{B}$ ) between the phenyl ring and the alkyl chain can change the mesomorphic behaviours. 
The ether linking group provides greater linearity to molecules rather than the ester group, thus resulting in the higher clearing point in compound $\mathbf{A}\left(T_{c}=\right.$ $\left.90.1^{\circ} \mathrm{C}\right)$ compared to compound $\mathbf{B}\left(T_{c}=85.6^{\circ} \mathrm{C}\right)$. This in turn results in wider larger phase width of SmA phase being observed in compound $\mathbf{A}(\triangle \mathrm{SmA}=$ $\left.8.2^{\circ} \mathrm{C}\right)$ compared to compound $\mathbf{B}\left(\Delta \mathrm{SmA}=4.8^{\circ} \mathrm{C}\right)$. Therefore, the ether linkage at the terminal position is more favorable to mesomorphism than the ester linkage. Subsequently, benzothiazole liquid crystals (12OMBBBZT, C, D and E) were built up with the ether linked to the terminal alkyl chain.

As a phenyl ring is added to the existing molecular structure of compound $\mathbf{A}$, this has resulted an extended core system with three ring molecule. It increased the clearing point of $12 \mathrm{OMBBBZT}$ to $217.9^{\circ} \mathrm{C}$. In addition, this extended core system is more adequate to generate mesophase because the SmA phase width increased dramatically from $8.2^{\circ} \mathrm{C}$ in compound $\mathbf{A}$ to $51.2^{\circ} \mathrm{C}$ in $12 \mathrm{OMBBBZT}$. Additionally, nematic phase was detected in 12OMBBBZT but not in the case of compound $\mathbf{A}$.

The dissimilarity between the molecules with three rings (12OMBBBZT and compound $\mathbf{C}$ ) is the linking unit that connected benzothiazole and aromatic rings. 12OMBBBZT possessed Schiff base linking group whereas compound C was without any linking group. 12OMBBBZT showed lower melting point $\left(110.6{ }^{\circ} \mathrm{C}\right)$ and larger SmA phase width $\left(\triangle \mathrm{SmA}=51.2{ }^{\circ} \mathrm{C}\right)$ compared to compound $\mathbf{C}$ (m.p. $=127.7^{\circ} \mathrm{C} ; \Delta \mathrm{SmA}=14.8^{\circ} \mathrm{C}$ ). Although Schiff base provides a stepped core structure, it maintains molecular linearity, therefore providing higher stability and enhancing formation of mesophase. Therefore, it can be assumed that Schiff base linking unit played an important role at suppressing the melting temperature and then, it widens the existing mesophase width.

Compounds D, E and 12OMBBBZT are having similar structure except for the additional substituent (methyl and ethoxy) at the sixth position of the benzothiazole ring for compound $\mathbf{E}$ and 12OMBBBZT. Compound D without the lateral substituent possessed lower clearing point $\left(179.6{ }^{\circ} \mathrm{C}\right)$ compared to compounds with lateral substituent, 12OMBBBZT (with methyl substituent, $217.9^{\circ} \mathrm{C}$ ) and compound $\mathbf{E}$ (with ethoxy substituent, $223.2^{\circ} \mathrm{C}$ ). This indicates that the incorporation of a small alkyl/alkoxy group at the lateral position of the benzothiazole ring can increase the clearing point of the molecule. This has also caused the nematic phase width increased from $15.0^{\circ} \mathrm{C}$ in compound $\mathbf{D}$ to $56.1^{\circ} \mathrm{C}$ in $12 \mathrm{OMBBBZT}$, to $64.7^{\circ} \mathrm{C}$ in compound $\mathbf{E}$. Therefore, it suggests that the lateral substituent at the benzothiazole ring able to widen the nematic phase width. Taking into account with the higher clearing point and broader nematic phase width in 12OMBBBZT and compound $\mathbf{E}$, it can be assumed that alkyl/alkoxy substituent at the lateral position of the current system, $\mathrm{C}_{6} \mathrm{H}_{4} \mathrm{COOC}_{6} \mathrm{H}_{4} \mathrm{C}(\mathrm{H})=\mathrm{NC}_{7} \mathrm{H}_{4} \mathrm{NS}$ can greatly enhance the mesomorphic properties. 
Table 3. Comparison of present series with reported liquid crystalline compounds (denotes as A, B, C, D and E) (where $\mathrm{n}=12$ )

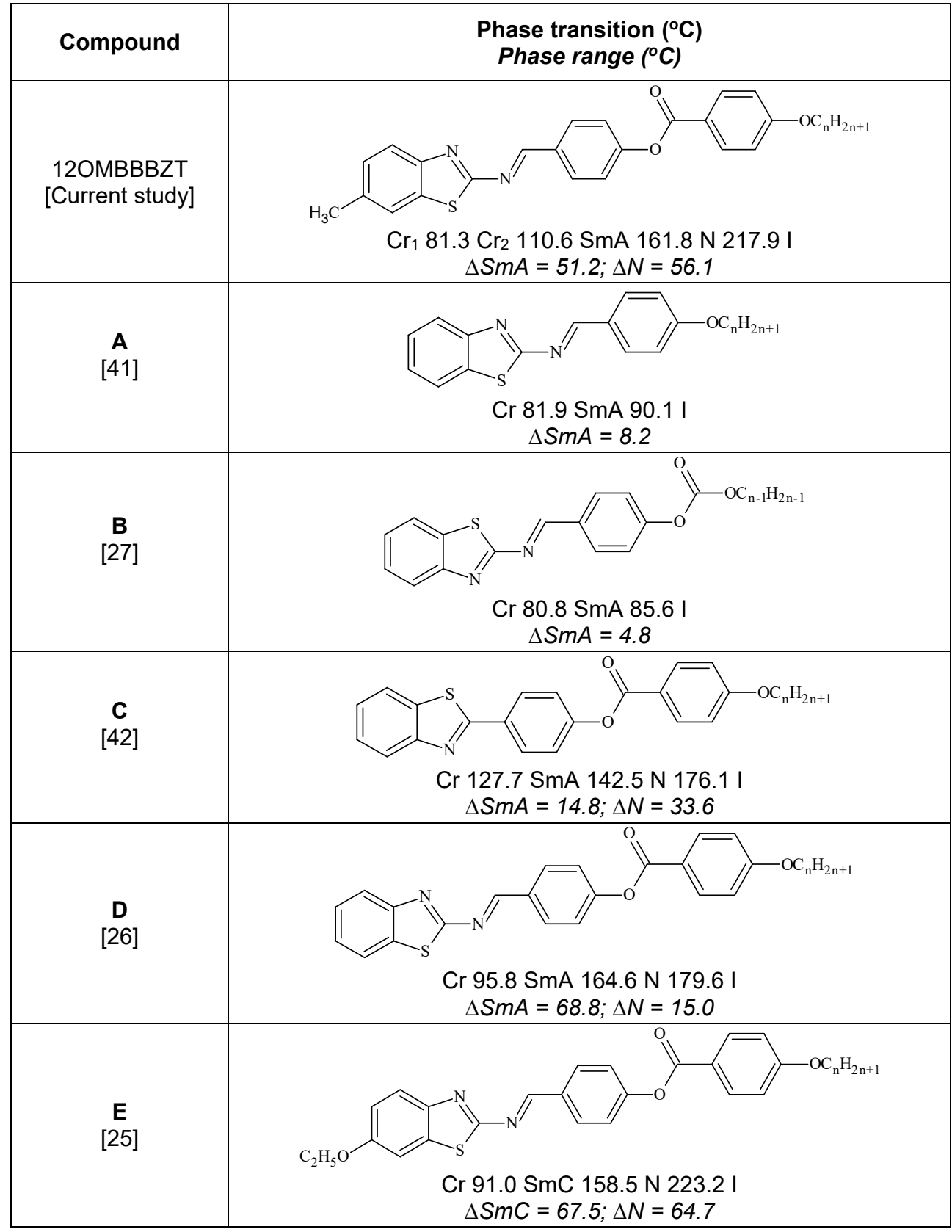




\section{CONCLUSIONS}

In this article, a new series of heterocyclic liquid crystals, 6-methyl-2[4-(4-alkoxybenzoyloxy)benzylideneamino]benzothiazoles is reported. The lowest member ( $n$-hexyloxy, C6) possesses the largest nematic phase width indicates that the current structure has a good mesogenic system for mesophase formation. The smectic phase was emerged from the $n$-dodecyloxy (C12) to $n$-hexadecyloxy (C16) derivatives. Hence, it can be concluded the current core system needs a specific alkoxy chain length $(n \geq 12)$ in order to produce SmA phase. Among these members (C6-C16), member with the longest terminal chain (C16) possessed the largest SmA phase width. The current finding considerably influence our future direction by using the current core system for producing new liquid crystal molecules.

\section{EXPERIMENTAL SECTION}

\section{Characterization}

Fourier-Transform Infrared (FT-IR) spectra of the synthesized compounds were collected using a Perkin-Elmer System 2000 FT-IR Spectrometer. All compounds were prepared as $\mathrm{KBr}$ pellets and analyzed with a measurement range of $4000-400 \mathrm{~cm}^{-1} .{ }^{1} \mathrm{H}$ NMR $(400 \mathrm{MHz}),{ }^{13} \mathrm{C} \mathrm{NMR}(100 \mathrm{MHz})$ and $2 \mathrm{D}$ $\mathrm{HMQC}$ spectra were recorded in $\mathrm{CDCl}_{3}$ solvent using a JEOL LA-400 MHz NMR spectrometer. Electron-ionization mass spectrometry, EI-MS (70 eV) was performed using a Mass Spectrometer Finnigan MAT95XL-T at a source temperature of $200^{\circ} \mathrm{C}$.

Mettler Toledo DSC823e differential scanning calorimeter was used to determine the phase transition temperatures and associated enthalpy changes at heating rate of $10{ }^{\circ} \mathrm{C} / \mathrm{min}$. Carl Zeiss polarizing optical microscope attached to a Linkam hotstage was utilized for temperature dependent studies of the mesophase textures. A video camera (Video Master coomo20P) installed on the microscope was connected to a video capture card (Video Master coomo600), allowing real-time video capture and image saving. The texture of liquid crystals exhibited by the compounds was observed using polarized light with crossed polarizers. Samples were prepared as thin films sandwiched between a glass slide and a cover slip. Phase identification was made by comparing the observed textures with those reported in the literature $[21,22]$.

Synchrotron powder X-ray diffraction (XRD) measurements were recorded using a beamline BL17A at the National Synchrotron Radiation Research Center (NSRRC) in Taiwan. The X-ray wavelength used was $1.32633 \AA$. The XRD data 
were collected using imaging plates (IP, of an area $=20 \times 40 \mathrm{~cm}^{2}$ and a pixel resolution of 100) curved with a radius equivalent to the sample-to-image plate distance of $280 \mathrm{~mm}$, and the diffraction signals were accumulated for three minutes. The powder samples were packed into a capillary tube and heated by a heat gun, where the temperature controller was programmed by a PC with a PID feedback system. The scattering angle theta was calibrated by a mixture of silver behenate and silicon.

\section{Synthesis}

All solvents and reagents were purchased commercially and used without any further purification. 4-Dimethylaminopyridine (DMAP), 4-hydroxybenzaldehyde, 1-bromoalkanes $\left(\mathrm{C}_{n} \mathrm{H}_{2 n+1} \mathrm{Br}\right.$ where $\left.\mathrm{n}=6,8,10,12,14,16\right)$, potassium hydroxide and potassium carbonate were purchased from Merck (Germany). Ethyl 4-hydroxybenzoate, 2-amino-6-methylbenzothiazole and $N, N$ '-dicyclohexylcarbodiimide (DCC) were supplied by Acros Organics (USA).

The synthetic route used for the preparation of nOMBBBZT is shown in Scheme 1. Steglich esterification between intermediate compounds, 6methyl-2-(4-hydroxybenzylideneamino)benzothiazole and 4-alkoxybenzoic acid were carried out according to methods described by Foo et al. [41] and Kadkin et al. [43], respectively. In the Steglich esterification, DCC is used as coupling agent and DMAP as catalyst. The water from this esterification is removed in dicyclohexylurea form [44].

\section{Synthesis of heterocyclic liquid crystals}

6-Methyl-2-(4-hydroxybenzylideneamino)benzothiazole ( $5 \mathrm{mmol}, 1.94 \mathrm{~g}$ ), appropriate 4-alkoxybenzoic acid ( $5 \mathrm{mmol})$ and DMAP (1 mmol, $0.12 \mathrm{~g})$ were dissolved in $40 \mathrm{~mL}$ mixture of dichloromethane (DCM) and dimethylformamide (DMF), and the solution was stirred at $0{ }^{\circ} \mathrm{C}$. DCC $(5 \mathrm{mmol}, 1.03 \mathrm{~g})$ dissolved in $10 \mathrm{~mL}$ of DCM was added into the mixture dropwise and the solution was continuously stirred for an hour at $0{ }^{\circ} \mathrm{C}$. The mixture was then stirred at room temperature for another five hours. Then, the mixture was filtered and the solvent was removed by evaporation. The obtained solid was repeatedly recrystallized from hexane and ethanol until the transition temperatures remained constant. The purity of all compounds was checked by thin layer chromatography (Merck $60 \mathrm{~F}_{254}$ ) and visualized under short-wave UV light. The IR and NMR $\left({ }^{1} \mathrm{H},{ }^{13} \mathrm{C}\right)$ for the representative compound, 14OMBBBZT, are summarized as follows.

IR $v_{\max }\left(\mathrm{KBr}, \mathrm{cm}^{-1}\right): 3017$ ( $v$ C-H aromatic), 2921, 2851 ( $v \mathrm{C}-\mathrm{H}$ aliphatic), 1726 ( $v \mathrm{C}=\mathrm{O}$ ester), 1601 ( $v \mathrm{C}=\mathrm{N}$ Schiff base, $\mathrm{C}=\mathrm{N}$ thiazole), $1576(v \mathrm{C}=\mathrm{C}$ aromatic), 1252 ( $v \mathrm{C}-\mathrm{O}$, aromatic ether); ${ }^{1} \mathrm{H} \mathrm{NMR}\left(400 \mathrm{MHz}, \mathrm{CDCl}_{3}\right): 0.88(t, 3 \mathrm{H}$, $\left.J=6.9 \mathrm{~Hz}, \mathrm{CH}_{3}-\right), 1.26-1.50\left(\mathrm{~m}, 22 \mathrm{H}, \mathrm{CH}_{3}-\left(\mathrm{CH}_{2}\right)_{11-}\left(\mathrm{CH}_{2}\right)_{2}-\mathrm{O}-\right), 1.81$ (quint, $2 \mathrm{H}$, 
$\left.J=7.0 \mathrm{~Hz},-\mathrm{CH}_{2}-\mathrm{CH}_{2}-\mathrm{O}-\right), 2.48$ (s, 3H, Ar- $\left.\mathrm{CH}_{3}\right), 4.03\left(t, 2 \mathrm{H}, J=6.9 \mathrm{~Hz},-\mathrm{CH}_{2}-\mathrm{O}-\right)$, $6.97(d, 2 \mathrm{H}, J=9.2 \mathrm{~Hz}, \mathrm{Ar}-\mathrm{H}), 7.28(d, 1 \mathrm{H}, J=8.2 \mathrm{~Hz}, \operatorname{Ar}-\mathrm{H}), 7.37(d, 2 \mathrm{H}$, $J=8.7 \mathrm{~Hz}, \mathrm{Ar}-\mathrm{H}), 7.62(s, 1 \mathrm{H}, \mathrm{Ar}-\mathrm{H}), 7.85(d, 1 \mathrm{H}, J=8.2 \mathrm{~Hz}, \mathrm{Ar}-\mathrm{H}), 8.09$ $(d, 2 \mathrm{H}, J=9.2 \mathrm{~Hz}, \mathrm{Ar}-\mathrm{H}), 8.14(d, 2 \mathrm{H}, J=8.7 \mathrm{~Hz}, \mathrm{Ar}-\mathrm{H}), 9.04(s, 1 \mathrm{H}, \mathrm{CH}=\mathrm{N})$; ${ }^{13} \mathrm{C} \mathrm{NMR}\left(100 \mathrm{MHz}, \mathrm{CDCl}_{3}\right): \delta 14.25\left(\mathrm{C}_{3}{ }^{-}\right), 22.80,26.08,29.18,29.47,29.66$, 29.70, 29.77, 32.03 for methylene carbons $\left(\mathrm{CH}_{3}-\left(\underline{\mathrm{CH}_{2}}\right)_{12-}\right), 21.72\left(\mathrm{Ar}-\mathrm{C}_{3}\right)$, $68.48\left(-\mathrm{CH}_{2} \mathrm{O}-\right), 114.49,121.04,121.58,122.65,122.75,128.14,131.57$, $132.38,132.50,134.81,135.45,149.82,155.02,163.90$ for aromatic carbons, 164.47 ( $\mathrm{C}=\mathrm{N}$ thiazole), 164.53 ( $\mathrm{C}=\mathrm{N}$ Schiff base), 170.78 (-ㅇO-).

\section{ACKNOWLEDGMENTS}

The authors would like to thank Universiti Tunku Abdul Rahman for the financial supports and research facilities.

\section{REFERENCES}

1. K.C. Zhao; J.Q. Du; H.F. Wang; K.Q. Zhao; P. Hu; B.Q. Wang; H. Monobe; B. Heinrich; B. Donnio; Chem. Asian J., 2019, 14(3), 462-470.

2. W. Zhang; T. Sakurai; M. Aotani; G. Watanabe; H. Yoshida; V.S. Padalkar; Y. Tsutsui; D. Sakamaki; M. Ozaki; S. Seki; Adv. Opt. Mater.; 2019, article number 1801349.

3. B.B. Chakraborty; S. Anwar; S. Das; S.B. Paul; G. Mohiuddin; J. De; S. Choudhury; Liq. Cryst.; 2018, 45(11), 1644-1653.

4. F.N. da Silva; A.S. da Silva; I.H. Bechtold; E. Zapp; A.A. Vieira; Liq. Cryst., 2019, 46(11), 1707-1717.

5. A.J. Seed; P. Sampson; Liq. Cryst., 2017, 44(12-13), 1894-1910.

6. E. Girotto, I.H. Bechtold, H. Gallardo; Liq. Cryst., 2016, 43(12), 1768-1777.

7. D. Shi, K. Hu; P. Chen; W. Du; A. Gao; R. Chen; X. Chen; Z. An; Liq. Cryst., 2016, 43(10), 1397-1407.

8. L.L. Lai; C.H. Wang; W.P. Hsien; H.C. Lin; Mol. Cryst. Liq. Cryst., 1996, 287, 177-181.

9. B.B. Chakraborthy; S. Anwar; S. Das; S.B. Paul; G. Mohiuddin; J. De; S. Choudhury; Liq. Cryst.; 2018, 45, 1644-1653.

10. M.L. Parra; E.Y. Qlgueta; J.A. Ulloa; J.M. Vergara; Al. Sanchez; Liq. Cryst., 2012, 39(8), 917-925.

11. J. Seltmann; M. Lehmann; Liq. Cryst., 2011, 38(4), 407-422.

12. W.L. Chia; C.W. Lin; Liq. Cryst., 2013, 40, 922-931.

13. M.Z. Shafikov, A.M. Prokhorov; D.W. Bruce; Liq. Cryst., 2017, 44(4), 705-712.

14. M. Hagar; H. Ahmed; O. Alhaddad; Liq. Cryst., 2019, 46(9), 1440-1451. 
15. P.J. Collings; M. Hird M; Introduction to Liquid Crystals: Chemistry and Physics, Taylor \& Francis Ltd., UK, 1998.

16. G. Karanlik; H. Ocak; B. Bilgin Eran; J. Mol. Liq., 2019, 275, 567-577.

17. M. Hagar; H.A. Ahmed; G.R. Saad; Liq. Cryst., 2018, 45(9), 1324-1332.

18. H.A. Ahmed; M. Hagar; T.H. El-Sayed; R.B. Alnoman; Liq. Cryst., 2019, 46(7), 1156-1166.

19. M. Hagar; H.A. Ahmed; G.R. Saad; J. Mol. Liq., 2019, 273, 266-273.

20. V.S. Sharma; R.B. Patel; Mol. Cryst. Liq. Cryst., 2017, 648(1), 53-65.

21. C. Selvarasu; P. Kannan; Mol. Cryst. Liq Cryst., 2017, 648(1), 77-87.

22. C. Selvarasu; P. Kannan; J. Mol Liq., 2016, 1125, 234-240.

23. B.T. Thaker; D.B. Solanki; B.S. Patel; N.B. Patel; Liq. Cryst., 2013, 40(9), 1296-1309.

24. V.S. Sharma; R.B. Patel; Mol. Cryst. Liq. Cryst., 2017, 643(1), 141-158.

25. T.M. Koh; S.T. Ha; G.Y. Yeap; H.C. Lin; Chin. Chem. Lett., 2013, 24, 926-928.

26. K.L. Foo; S.T. Ha; G.Y. Yeap; H.C. Lin; Phase Trans., 2019, 92(1), 87-99.

27. S.T. Ha; T.M. Koh; H.C. Lin; G.Y. Yeap; Y.F. Win; S.T. Ong; Y. Sivasothy; L.K. Ong; Liq. Cryst., 2009, 36(9), 917-925.

28. G.Y. Yeap; T.C. Hng; D. Takeuchi; K. Osakada; W.A.K. Mahmood; M.M. Ito; Mol. Cryst. Liq. Cryst., 2009, 506, 134-149.

29. G.M. Paterno; V. Robbiano; K.J. Fraser; C. Frost; V. Garcia Sakai; F. Cacialli; Sci. Rep., 2017, 7, 41013.

30. D. Demus; L. Richter; Textures of Liquid Crystals, Verlag Chemie, New York, 1978.

31. I. Dierking, Textures of Liquid Crystals, Wiley-VCH, Weinheim, 2003.

32. B.Y. Zhang; Y.G. Jia; D.S. Yao; X.W. Dong; Liq. Cryst., 2004, 31, 339-345.

33. D. Pociecha; D. Kardas; E. Gorecka; J. Szydlowska; J. Mieczkowski; D. Guillon; J. Mater. Chem., 2003, 13, 34-37.

34. R.A. Reddy; B.K. Sadashiva; J. Mater. Chem., 2004, 14, 310-319.

35. K.C. Majumdar; S. Mondal; N. Pal; P.K. Sinha; Tetrahedron Lett., 2009, 50, 1992-1995.

36. Q. Wei; L. Shi; H. Cao; L.P. Wang; H. Yang; Y.B. Wang; Liq. Cryst., 2008, 35, 581-585.

37. G.W. Gray; Molecular Structure and the Properties of Liquid Crystals, Academic Press, London, 1962.

38. P. Berdague; J.P. Bayle; M.S. Ho; B.M. Fung; Liq. Cryst., 1993, 14, 667-674.

39. P.J. Collings; M. Hird; Introduction to Liquid Crystals: Chemistry and Physics, Taylor \& Francis Ltd., UK, 1998.

40. G.Y. Yeap; S.T. Ha; P.L. Lim; P.L. Boey; M.M. Ito; S. Sanehisa; Y. Youhei; Liq. Cryst., 2006, 33(2), 205-211.

41. K.L. Foo; S.T. Ha; F.W. Yip; G.Y. Yeap; H.C. Lin; S.S. Sastry; Liq. Cryst., 2014, 41(11), 1516-1525.

42. S.T. Ha; T.M. Koh; F.W. Yip; S.S. Sastry; Liq. Cryst., 2013, 40(8), 1016-1023.

43. O.N. Kadkin; H. Han; Y.G. Galyametdinov; J. Organomet. Chem., 2007, 692, 5571-5582.

44. A.B. Lutjen, M.A. Quirk, A.M. Barbera, E.M. Kolonko; Bioorg. Med. Chem., 2018, 26, 5291-5298. 